\title{
Meralgia paraesthetica (Bernhardt-Roth syndrome)
}

M eralgia paraesthetica (Bernhardt-Roth syndrome) is a distinctive condition, more common in men than in women, characterised by paraesthesiae and often burning pain over the anterolateral aspect of the thigh. Impaired or altered sensation is found in the same area, but there is no motor weakness or wasting and the knee jerk is preserved, distinguishing it from radiculopathy. Prolonged standing, or sitting with the thigh extended, may provoke symptoms because hip extension increases angulation and tension on the lateral femoral cutaneous nerve (LFCN), whereas flexion of thigh on the pelvis improves symptoms by decreasing these forces. The incidence is estimated at 4 per 10000 person years. ${ }^{1}$

Martin Bernhardt (1844-1915), a German neuropathologist first depicted the condition in $1878 .^{2}$ His second paper $^{3}$ describes:

"In some there was a connection most probably existing, more or less severe neuritis at the femoral ring where the $N$. cutaneous externus femoris and its branches pass. Infections- (typhoid fever) or intoxications (lead poisoning) or with cold (intensive cooling through too cold Douches) have been proved. ... It is interesting, that in two of my patients (a Smelter and a Smith) the legs especially, suffer after a sudden chill ..."Sensibility to be proved objective, remained severely restricted in the distribution zone of the $\mathrm{N}$. cutaneous femoris externus, ... a true anaesthesia existed in no case." (Author's translation)

A student of Rudolf Virchow (1821-1902), Bernhardt worked at Westphal's clinic at the Berlin Charité as a neuropathologist until 1882 when he was appointed "extra-

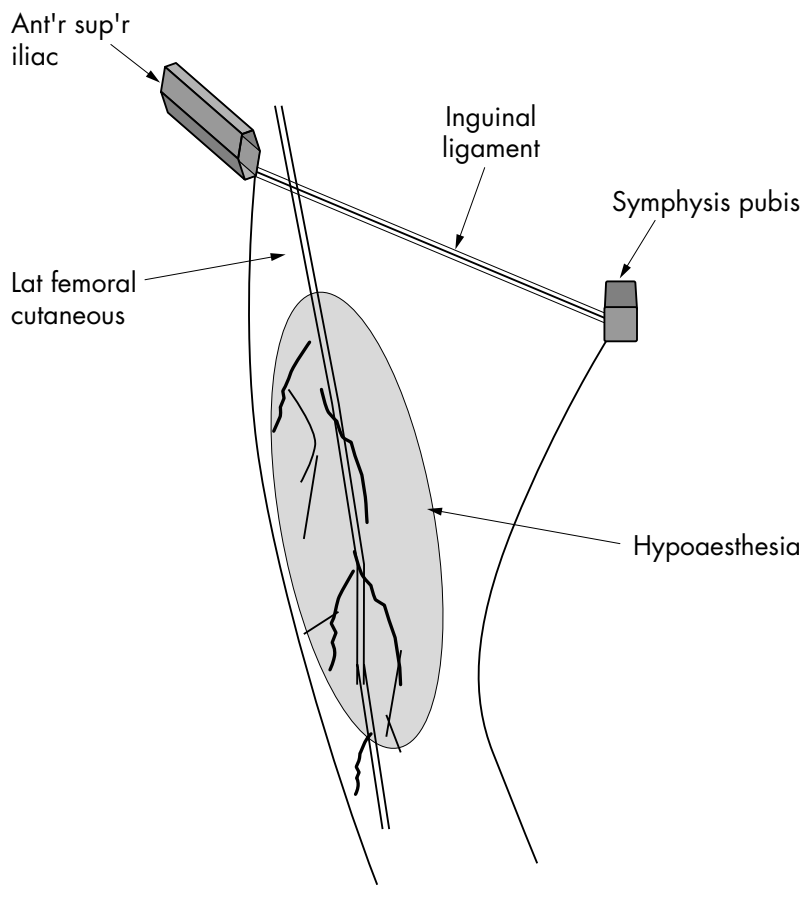

Figure 1 Lateral femoral cutaneous nerve (L2-L3) passing under inguinal ligament to innervate anterolateral skin of thigh. ordinary physician" at the Berlin faculty of medicine. He served in the army 1870-1871. He retired from his polyclinic in 1914 and died a year later. (In Virchows Archiv, 1893, he also described a familial form of spinal progressive scapulohumeral muscular atrophy known as Vulpian-Bernhardt spinal muscular atrophy).

Vladimir Karlovich Roth (1848-1916) was a distinguished Russian neurologist, who coined the term meralgia paraesthetica in a 24 page booklet. ${ }^{4}$ He noticed it in cavalrymen, who wore their belts too tightly, which compressed the emerging femoral cutaneous nerve. He read Medicine at Moscow, and from 1877 to 1879 worked in clinics in Paris, Berlin, and Vienna before leading the neurology unit (1881-90) at the Staro-Ekaterinska hospital in Moscow. From 1902 Roth held the chair of Neurological Diseases at the Moscow University.

Interestingly, Sigmund Freud (1895) reported that he and one of his sons had this condition. ${ }^{5}$

The anatomy of the LFCN is variable. ${ }^{6}$ Compression in the groin is the common cause. The union of the posterior branches of the L2 and L3 roots forms the LFCN. It emerges from the lateral border of the psoas major, and crosses the Iliacus obliquely, toward the anterior superior iliac spine (ASIS). It then passes under the inguinal ligament over the sartorius into the thigh, where it divides into anterior and posterior branches that pierce the fascia lata. The common site of compression is between the fascia and the inguinal ligament. Proximal compression by retroperitoneal haematomata or tumours is rare, but occasional instances follow iliac bone graft harvesting, pelvic surgery via an ilioinguinal approach, laparoscopic appendicectomy, femoral artery catheterization, and hip or lumbar spinal surgery in the prone position. Entrapment is often caused by clothing that is too tight, ${ }^{7}$ or by long distance walking or sports, including cycling. It may be associated with pregnancy and weight change.

Electrodiagnostic tests are superfluous. Conservative treatment aimed at removing sources of compression is usually successful. Neurectomy with excision of a portion of the LFCN may be needed for intractable symptoms; but it leaves a permanently numb, though usually painless, area in the nerve territory.

\section{J M S Pearce \\ Emeritus Consultant Neurologist, Department of Neurology, Hull Royal Infirmary, 304 Beverley Road Anlaby, East Yorks, HU10 7BG, UK; jmspearce@freenet.co.uk \\ Competing interests: none declared}

\footnotetext{
References

1 van Slobbe AM, Bohnen AM, Bernsen RM, et al. Incidence rates and determinants in meralgia paresthetica in general practice. J Neurol 2004;25:294-7.

2 Bernhardt M. Neuropathologische Beobachtungen. Deutsches Archiv für klinische Medicin. Leipzig 1878;22:362-93.

3 Bernhardt $M$. Ueber isoliert im Gebiete des $N$. cutaneus femoris externus vorkommende Paräesthesien. Neurologisches Centralblatt 1895;14:242-4.

4 Roth WK. Meralgia paraesthetica. Berlin: Karger, 1895.

5 Freud S. Ueber die Bernhardtsche Sensibilitaetsstoreung. Neurol Centralbl 1895; 14:491-492.

6 de Ridder VA, de Lange S, Popta JV. Anatomical variations of the lateral femoral cutaneous nerve and the consequences for surgery. J Orthop Trauma 1999; 13:207-11.

7 Boyce JR. Meralgia paresthetica and tight trousers. JAMA 1984;251:1553.
} 